\title{
Economic Analysis of the Use of Tissue Culture for Rapid Forest Improvement
}

\author{
by \\ Sadiq Hasnain ${ }^{1}$, René Pigeon ${ }^{2}$, and Ralph P. Overend ${ }^{1}$
}

\begin{abstract}
The economic feasibility of the use of tissue culture in forestry for planting stock production depends on two main conditions. One is the ability to produce sufficient genetic gain in a breeding program through controlled crosses, while the other depends on the utilization of the genetic gain (i.e. increased growth rate) to reduce rotation age. The cost of tissue culture plantlets will be relatively high, but will be more than compensated by the savings realized due to a shorter growth period.
\end{abstract}

\section{Résumé}

La utilisation de la culture de tissu pour la production de plants de reforestation serra rentable à deux conditions. La première est la possibilité de produire des gains génétiques suffisants dans un programme réalable d'amélioration par pollinisation sélective. La deuxième condition est la possibilité que les gains génétiques dans le taux de croissance permettent de rapprocher l'âge de la récolte. Le coût des plants par culture de tissu serra rélativement élevé mais serra plus que compensé par l'économie réalisée à la suite d'une période de croissance abrégée.

\section{Introduction}

The concept of clonal forestry is gaining increased recognition as a means for achieving more rapid forest improvement and increased forest productivity (Farnum et al 1983, Rauter 1983, Zobel and Talbert 1984, Timmis 1984 , Smith 1986). The application of clonal forestry relies on the ability to propagate planting stock of superior quality by vegetative methods. Currently in forestry there are two distinct methods for vegetative propagation. One relies on obtaining stem cuttings and subsequent rooting. This method, referred to as macropropagation, has been used in Japan for Cryptomeria japonica for centuries and is now increasingly being used in other countries for hardwoods such as hybrid poplar (Populus spp.) and eucalyptus (Eucalyptus spp.) and softwoods such as Norway spruce (Picea abies [L.] Karst.), and black spruce (Picea mariana Mill.). The other method uses the technique of culturing asceptically, in vitro, small amounts of tissue either from juvenile sources, such as embryos or cotyledons, or from mature sources, such as shoot meristems or needle fascicles (Thorpe and Biondi 1984, Mason and Maine 1984), and is referred to as micropropagation.

Micropropagation from juvenile tissue has been demonstrated at the laboratory bench for many conifers and demonstrated at a field trial stage most notably for Douglas-fir (Pseudostuga menziesii [Mirb.] Franco) (Ritchie and Long 1985), Ioblolly pine (Pinus taeda L.) (Frampton 1985), and radiata pine (Pinus radiata D. Don) (Smith et al 1986). To date

NRCC 25027, Division of Energy, Division of Biological Sciences, National Research Council of Canada, Ottawa, Canada K1A OR6

2Industrial Policy Analysis, National Research Council of Canada, Ottawa, Canada K1A OR6 only two groups have done an economic analysis of micropropagation, one at the Forest Research Institute (FRI) in New Zealand (Smith 1986) and the other at Weyerhaeuser in Washington State (Timmis 1984). While Weyerhaeuser's detailed results are proprietary, Timmis concluded that, under a certain set of forestry assumptions, micropropagation is economic. Smith, at the FRI, showed through a preliminary analysis that the use of micropropagated plantlets could be cost effective compared with the use of seedlings on the basis of conservative estimates of increased genetic gain of planting stock and a reduced planting density (due to improved quality and form and therefore a reduced requirement for thinning). In this paper we present the first detailed description of the sensitivity of the cost of producing micropropagated plantlets to changes in the various parameters in the upstream stages of micropropagation. Also presented is a cost/benefit analysis of micropropagation compared with the use of conventional seedlings for forest regeneration. For a detailed discussion of tissue culture and its relationship to tree and forest improvement refer to a previous article in this journal (Hasnain and Cheliak 1986) which serves as a background to this paper and a review of the use of tissue culture in forestry.

\section{Methods}

In Canada all tissue culture and micropropagation work on conifers has been at the laboratory research scale. Even for those species for which the protocols for micropropagation have been established, not enough information is available to enable us to perform a fully independent cost evaluation. Therefore the authors have used data derived by Smith (1986) on radiata pine at FRI in New Zealand. Table 1 shows Smith's 
Table 1. Breakdown of costs of conifer micropropagation

\begin{tabular}{|c|c|c|c|c|c|}
\hline \multicolumn{2}{|l|}{ New Zealand Data (Smith 1986) } & \multicolumn{4}{|c|}{ Canadian Data } \\
\hline $\begin{array}{l}\text { Phase of } \\
\text { operation }\end{array}$ & Cost $\%$ & $\begin{array}{l}\text { Phase of } \\
\text { operation }\end{array}$ & Cost $\%$ & $\begin{array}{c}\text { Annual } \\
\text { cost } \\
\text { (k\$) }\end{array}$ & $\begin{array}{c}\text { Present } \\
\text { value } \\
(\mathbf{k} \$)\end{array}$ \\
\hline Labour 3 & 25.2 & Labour ${ }^{3}$ & 29.2 & 141 & 991 \\
\hline Capital $^{4}$ & $9 . \overline{6}$ & Capital7 & 5.2 & 175 & 175 \\
\hline Consumables 5 & 2.7 & Consumables 8 & 3.6 & 18 & 124 \\
\hline Auxin treatment & & Auxin treatment & & & \\
\hline Root propagation & & Root propagation 9 & & & \\
\hline Labour & 31.3 & Labour & 29.8 & 144 & 1008 \\
\hline Capital & 5.5 & & & & \\
\hline Lining out & & Greenhouse ${ }^{10}$ & 21.8 & 100 & 738 \\
\hline Labour & 7.6 & & & & \\
\hline Tending, lifting, bagging & & & & & \\
\hline
\end{tabular}

${ }^{3}$ Assuming $100 \%$ process efficiency, shoot production rate $90 / \mathrm{h}$, labour cost $7.00 \mathrm{SNZ} / \mathrm{h}$.

${ }^{4}$ Discounted at $10 \% /$ a over 10 years.

5Does not include power for heating and lighting.

ESame as $N 2$ except primary shoot separation at $35 / \mathrm{h}$ is included and Canadian wage rate of 9 \$ $/ \mathrm{h}$ is used.

${ }^{7}$ Discounted at $7 \% / \mathrm{a}$ before tax and over 10 years.

8 Does not include utilities.

$990 \%$ rooting efficiency

10Plantlets are grown for 1 year in greenhouse.

breakdown of the costs associated with the different stages of micropropagation. Since climatic conditions differ in Canada, the FRI data beyond the root formation stage could not be used. Our model has also been adapted to include a bud initiation stage (primary bud production). We independently calculated the size of the tissue culture facility and used Canadian rates for labour and construction costs. The labour required for the in vitro stage was derived directly from the shoot separation rates of 35 shoots/h for primary shoots (Smith, personal communication) and 90 shoots/h for secondary shoots (Smith 1986). The New Zealand data were used to derive the Canadian costs of consumables and the labour required during the auxin treatment and root propagation phases

Table 2 lists the physical and financial assumptions used in the model for calculating the cost of producing micropropagated plants. The capacity of the tissue culture facility was arbitrarily selected at about one million plantlets per year, requiring a space of about $230 \mathrm{~m}^{2}$. There would probably be some small economy for larger facilities than this. The rooted micropropagated plants must be grown to a suitable size and hardened off for planting. For this we estimate that the micropropagated plantlets would have to spend one season in a greenhouse, for which we have

Table 2. Physical and financial assumptions for calculating tissue culture costs ( $\$$ C 1984)

\begin{tabular}{lc}
\hline Facility (year 0 ) & $175 \mathrm{k} \$$ \\
$\quad-232 \mathrm{~m}^{2} @ \$ 753 / \mathrm{m}^{2}$ & 10 years \\
Payback period & $23 \mathrm{k} \$ / \mathrm{a}$ \\
Consumables (year 1 to 10) & $18 \mathrm{k} \$ / \mathrm{a}$ \\
Wage & $18 \mathrm{PY} / \mathrm{a}$ \\
$\quad$ - at $9 \$ / \mathrm{h}$ with fringe benefits & $100 \$ / \mathrm{a} . \mathrm{k} /$ plantlets \\
Labour & $7 \% / \mathrm{a}$ \\
Greenhouse cost (year 2$)$ & \\
$\quad-1$ year in greenhouse & \\
Rea discount rate & \\
a.k./plantlet - before tax &
\end{tabular}

assigned a cost of $\$ 100$ per 1,000 plantlets or one half the estimated cost of 2-year-old seedlings in British Columbia (David Simpson, BC Ministry of Forestry, personal communication). The life of the facility, which is expected to be built at an existing conifer seedling nursery, was taken as 10 years, assuming that a small business would have to justify its loan on a payback period shorter than the full life of the facility. If the facility were built and owned instead by a provincial government nursery, a life of 20 years would be more appropriate and result in a slightly lower cost. A real discount rate of $7 \%$ / a before tax is applied for assessing the value of tissue culture from the viewpoint of the government (social discount rate); $7 \% / \mathrm{a}$ is also a convenient (weighted average) discount rate for many private sector decision makers who rely on a rather high debt to equity ratio of capital.

Table 3 is a summary of some of the parameters that describe what may be considered as a generic conifer tissue culture process. It was assumed that for each source of juvenile tissue (either germinated embryos or cotyledons), 10 adventitious buds can be induced. Each bud can be elongated and put through a system of remultiplication, probably through axillary bud formation, to give a 5 -fold secondary multiplication. Each secondary multiplication cycle is 12 weeks long and three of these cycles would be feasible in one year for an overall multiplication rate of 1250 . Therefore, if 1000 seeds are used, 1250000 shoots can be produced in one year. Finally, if the rooting efficiency for the shoots is $90 \%$. the output of the facility would be 1125000 rooted plantlets. These plantlets would then spend another year in a greenhouse for growing and acclimatizing. As the facility takes one year to build, the first output would occur at year 3 and continue to year 12 . Once the individual cost components for micropropagation have been calculated and the final output of plantlets determined, a supply price can be calculated.

Since micropropagated plantlets are expected to cost more than seedlings, a comparison can only be made on the assumption that by using micropropagation, and therefore 
Table 3. Tissue culture base case parameters

Starting number of seeds

- seed germinated

- buds induced on cotyledons

or embryos

Number of primary buds per embryo

- buds are elongated and

separated for secondary multiplication

Number of secondary buds - axillary buds are elongated and separated for re-multiplication

Number of secondary multiplications 12 weeks/cylce

Primary shoot separation rate

- rate of separation of shoots produced from primary buds

Secondary shoot separation rate

Root formation efficiency

Output of plantlets

1000

3

$35 / h$

$90 / \mathrm{h}$

$90 \%$

$1,125 \mathrm{k}$ plants / a

clonal forestry, some additional quantifiable advantage can be gained when the trees are harvested. This advantage or gain may be simply increased yield due to faster growth and/or to disease resistance, or it may be expressed in some other trait such as higher specific gravity, increased cellulose content, lower lignin content, or even improved form which may have a bearing on harvesting costs. The additional future value accrued from the superior stock must be sufficiently large so that, after it is discounted back to present value over the rotation age, the increased revenues generated from the sale of the wood by the landowner must at least break even with the cost increase associated with the use of the micropropagated stock instead of seedlings. A comparison between two technology options can be done through a net present value analysis. Net present value is derived by first converting all costs and revenues into present values (in this case of the year 1984) with the selected discount rate and then by subtracting the total discounted costs from the sum of discounted revenues. In our case, for simplification, we shall only consider the costs of producing seedlings and micropropagated plantlets since planting and tending costs would be the same in both scenarios. We have also assumed similar planting densities for both scenarios although it would be possible in certain forest managment schemes to plant fewer micropropagated plantlets per hectare since genetic uniformity would lead to more uniform stands. This would reduce or eliminate the need to thin out substandard stems as discussed by Smith (1986), or perhaps improve viability.

Table 4 lists the downstream base case parameters used for determining the present value of the mature trees that were planted either as seedlings or micropropagated plantlets. For the rotation age we have used 60 years for both the micropropagated and seedling stock in the base case. We expect that 60 years is a sufficient time on productive sites to produce a crop under intensive management. The yield was estimated as $450 \mathrm{~m}^{3} /$ ha after 60 years. Finally, to calculate the sales value of the stock a stumpage price had to be assigned that would allow recovery of the investment in the seedlings after 60 years. We calculated that the stumpage price that would have to be charged to just break even with the initial cost of 1000 seedlings is $\$ 26 / \mathrm{m}^{3}$ assuming a cost of $\$ 200 / 1000$ seedlings, a planting density of 1000 stems/ha and a yield of $450 \mathrm{~m}^{3} / \mathrm{ha}$ after 60 years. The current stumpage rates are lower than this, but to do an economic analysis a stumpage rate that reflects the regeneration costs is required. For this season we decided to use a shadow stumpage price of $\$ 50 / \mathrm{m}^{3}$. It is of interest to note that in New Zealand the 1983
Table 4. Downstream base case parameters

Seedling production cost

containerized and grown for

2 years

Planting density

Rotation age

Yield

Stumpage shadow price

$200 \$ / k$ plants

1000 stems/ha

$60 \mathrm{a}$

$450 \mathrm{~m}^{3} / \mathrm{ha}$

$50 \$ / \mathrm{m}^{3}$

stumpage price paid for 30-year-old trees for timber from a pruned stand was $\$ 50 \mathrm{NZ} / \mathrm{m}^{3}$ (Smith 1986) (1983 New Zealand dollar exchanged for approximately $\$ 0.80$ Canadian).

\section{Results}

Under the base case assumptions listed in Tables 2 and 3 , the cost of producing micropropagated conifer plantlets in Canada is $\$ 491$, of which $\$ 384$ is due to micropropagation and about $\$ 107$ to the final greenhouse stage.

Table 1 lists the percent contribution of the different steps to the final cost. The capital cost of $\$ 175000$ for building the tissue culture facility is only $5 \%$ of the total cost of producing micropropagated plantlets ready for planting. Consumables, at an annual cost of $\$ 23000$, are also about $5 \%$ of the total cost while the labour for micropropagation up to the rooting stage constitutes $68 \%$. The final greenhouse stage is about $21 \%$ of the final cost.

Sensitivity analyses were done for a number of parameters including primary multiplication, secondary multiplication, shoot separation rate, rooting efficiency, labour reduction and capital cost (Figure 1). Since capital cost is only $5 \%$ of the total cost, wide variation from the base case cost of $\$ 753 / \mathrm{m}^{2}$ for building the facility does not have a very significant effect on the cost of plantlets. Similarly, a 25 to $50 \%$ increase in the cost of consumables does not have a significant effect. The effect of increasing the primary and secondary multiplication factors is interesting. Both cost curves drop steeply and then level off giving no significant decrease in cost with increasing multiplication factor. This levelling off is due to the fact that as the number of shoots increase, more labour is required to separate them at a fixed shoot separation rate. The cost curve for the primary multiplier starts to level off at a multiplication factor of about five whereas the base case value selected for this paper is 10 . For most conifers the formation of 10 to 30 primary buds is common (Thorpe and Biondi 1984). For secondary multiplication, the curve starts to level off at a multiplication factor of four and a cost of about $\$ 520$ while the base case value selected was five giving a cost of $\$ 491$. Smith (1986) reported a secondary multiplication rate of 4 to 6 for each 12week cycle. The secondary multiplication rate depends on the method used. If axillary budding is induced on the primary shoots, a multiplication rate of 4 to 6 is expected. If adventitious shoots are induced, the multiplication rate can be 10 or more. There is, however, some controversy on the possibility of introducing genetic instability through adventitious bud production (D'Amato 1975, Bayliss 1980). More recent publications (Dolezel and Novák 1984a, Dolezel and Novák 1984b) suggest that genetic stability in tissue culture may be dependent on techniques and/or methods rather than a general phenomenon.

Shoot separation, which is the stage at which shoots are dissected, separated and transferred from one container to 


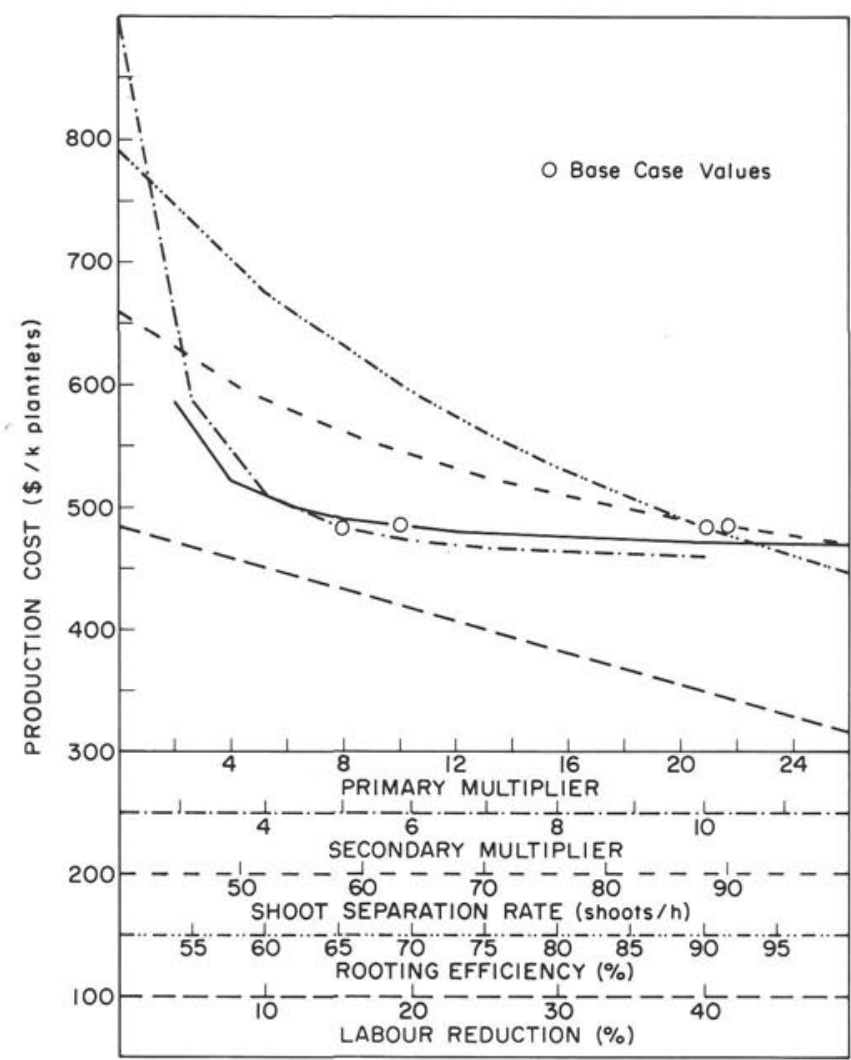

Figure 1. Sensitivity analysis of tissue culture parameters.

another, is one of the most labour intensive components of micropropagation, making up about $29 \%$ of the total cost. Under the standard procedure for micropropagating conifers, shoot separation is required at two stages. The first is after elongation and shoot formation from the primary buds induced on the embryo or cotyledon; the second is after secondary bud formation (on the primary shoots) and elongation of the secondary shoots. As the base case in this paper, a primary shoot separation rate of 35 shoots/h (Smith, personal communication) and a secondary shoot separation rate of 90 shoots/h (Smith, 1986) were used. Primary shoot separation does not have an important bearing on cost since the number of shoots that have to be handled at this stage is still small. However under the protocol used in this paper, the secondary shoot separation rate does affect cost. A reduction from the base value of 90 shoots/h to 50 shoots/h increases cost by over $\$ 100 / 1000$ plantlets. Rooting efficiency is another important parameter affecting cost. A drop in rooting efficiency from the base case value of 90 to $60 \%$ increases cost by about $\$ 100$.

Since micropropagation is labour intensive, the effect of reducing labour on production cost was determined. A $25 \%$ reduction in labour decreases cost by about $\$ 100$. Since some recent developments such as somatic embryogenesis of Norway spruce in Sweden (Hakman, Fowke, von Arnold and Eriksson 1985) and the development of new micropropagation protocols for radiata pine in New Zealand which may enable very high shoot separation rates of up to 600 shoots $/ \mathrm{h}$ (Aitken-Christie 1985), labour reduction of 25 to $50 \%$ is a distinct possibility. Figure 2 shows the effect of labour reduction on cost at two different rooting efficiencies, 80 and $90 \%$. The results suggest that in certain situations lower rooting efficiencies could be tolerated if there were a concommitant improvement in another area of the technology that resulted in labour reduction.

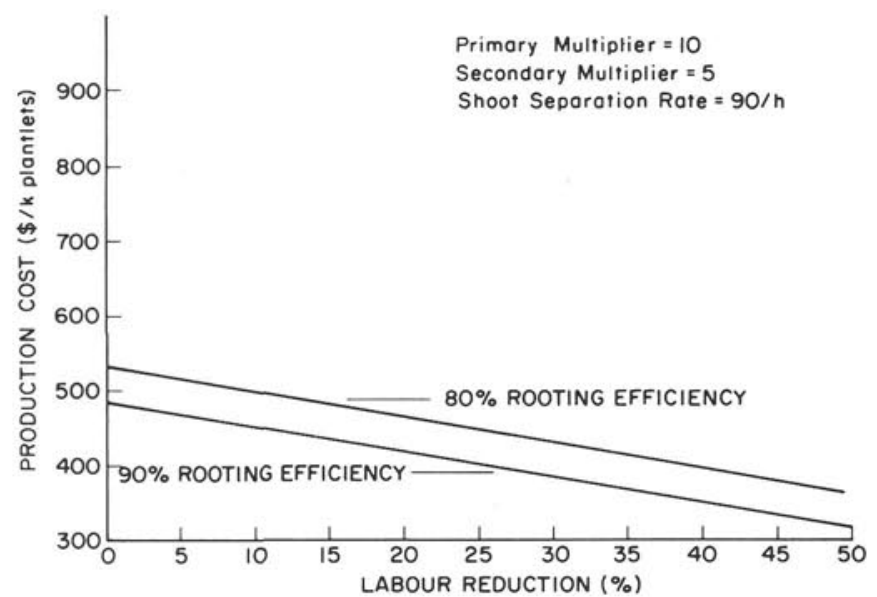

Figure 2. Effect of labour reduction on cost at 80 and $90 \%$ rooting efficiency,

Figure 3 shows a cost-benefit analysis of using micropropagated plantlets for forest regeneration instead of seedlings. To do the analysis, a net present value of the future forest harvest was determined using a yield of $450 \mathrm{~m}^{3}$, a $\$ 50$ stumpage shadow price, a cost of seedlings of $\$ 200 / 1000$ plants, the calculated cost of micropropagated plantlets of $\$ 491$, and increasing values of genetic gain. As mentioned earlier, since the micropropagated plantlets are more costly, to justify their use some additional advantage must be gained over seedlings that will result in a higher return at harvest. Figure 3 shows the amount of increased yield due to genetic gain that would be required, using micropropagated plantlets, to break even or do better than seedlings. On the $y$ axis is the cost ratio of micropropagated plantlets to seedlings (calculated in the base case to be 2.45), and on the $x$ axis is the average annual rate of genetic gain for a 60 -year rotation. In this case the advantage of using micropropagated plantlets is simply an increased yield while maintaining rotation age constant. Calculation of net present value (NPV) ratio for the use of tissue culture relative to seedlings shows that, just to break even with the use of seedlings, the use of micropropagated plantlets would have to deliver about a $75 \%$

NET PRESENT VALUE RELATIVE TO SEEDLINGS

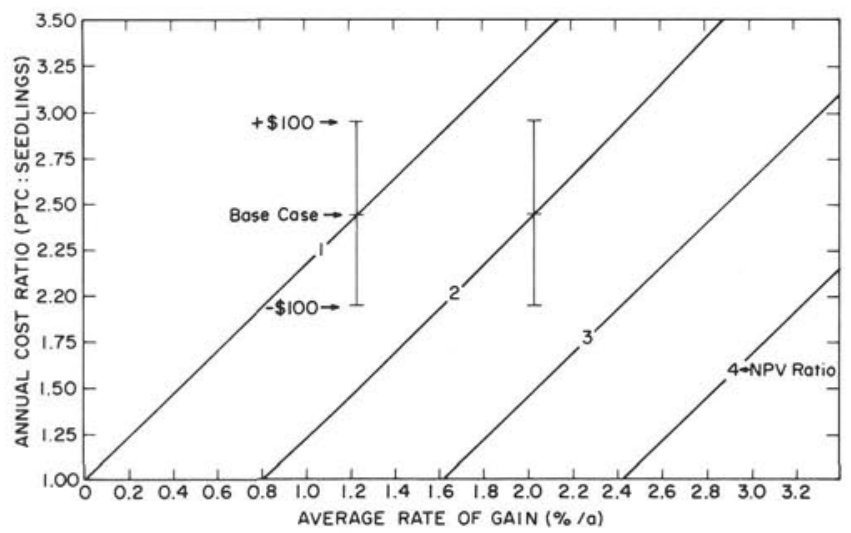

Figure 3. Cost/benefit analysis of using tissue cultured plantlets instead of seedlings. With rotation age constant at 60 years, the required amount of additional genetic gain that must be delivered through tissue culture to break even with seedlings (net present value $($ NPV) ratio $=1$ ) can be determined for any annual cost ratio of tissue cultured plantlets to seedlings (base case value of 2.45). The effect of increasing and decreasing the cost of tissue culture by $\$ 100$ is indicated. 
increase in yield (annual average rate of gain of $1.25 \%$ ). To obtain an NPV ratio of 2, an increased yield of about $125 \%$ would be required (annual average rate of gain of $2 \%$ ). Clearly this level of genetic gain is unrealistic.

Figure 4 shows a different method of exploiting genetic gain. In this scenario, instead of increasing yield at a fixed rotation age of 60 years, genetic gain is utilized to decrease rotation age. Since time has an exponential effect on the present value and therefore NPV, decreasing rotation age has a much greater influene on the economics of using micropropagation than increasing yield. In this case, reducing the rotation age to 51 years, which is equivalent to $30 \%$ gain, allows micropropagation to break even with seedlings. Reducing the rotation age to 48 years, which is equivalent to a genetic gain of $40 \%$, gives an NPV ratio of 2 , while a rotation age of $45(50 \%$ genetic gain) gives an NPV ratio of 3 . If the expectation of a $25 \%$ labour reduction is realized, resulting in a decrease in the price of micropropagated plantlets by $\$ 100 /$ 1000 plantlets, then a $33 \%$ increase in genetic gain would give an NPV ratio of 2.

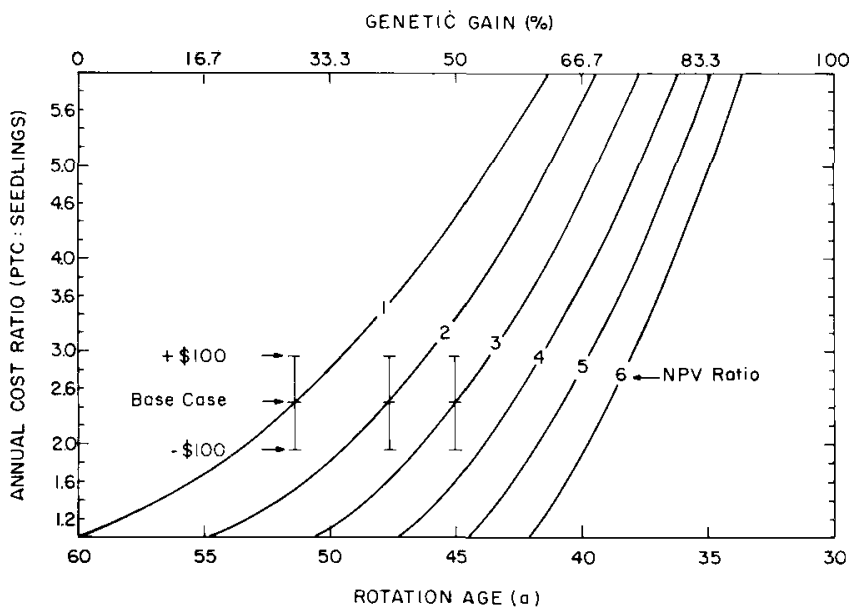

Figure 4. Same as Figure 3 except that the additional genetic gain delivered through tissue culture is used to decrease rotation age while maintaining yield constant at $450 \mathrm{~m}^{3}$ ha. Reducing the time required for return on investment has a greater effect on the cost effectiveness of tissue culture than increasing yield and, therefore, less genetic gain is required to break even or do better than seedlings.

\section{Conclusions}

Under the assumptions detailed in this paper, the use of micropropagation is expected to be competitive with seedlings costing $\$ 200$ per 1000 if the micropropagated plantlets have increased growth rates of $30 \%$ (but only if this results in a reduction of rotation age of 9 years). Work done at Weyerhaeuser in Washington State (Timmis 1984) has shown, for example, that in one control mating study on Douglas-fir, 12 full-sib families out of the 100 had mean volumes, measured at age 6 , of $30 \%$ or higher than the mean volumes of trees from wild seed collected from the area, while three families were about $50 \%$ higher.

The potential for even greater gains exists if progeny trials within full-sib families are carried out (Hasnain and Cheliak 1986). Even if effective methods could be developed to produce full-sib seed at an operational scale for forest regeneration, it would take 15 years or longer to deliver commercial quantities of seed than if micropropagation were used for planting stock production. Moreover seed production would not allow the exploitation of any of the useful intra-family variation. There is also significant potential for reducing costs of micropropagated plantlets through further research and development and implementing recent advances in tissue culture methods, such as the increased shoot separation and multiplication rates reported by $\mathrm{FR} I$ in New Zealand (AitkenChristie 1985) and the somatic embryogenesis of Norway spruce achieved in Sweden (Hakman et al 1985). Reductions in the cost of micropropagated plantlets will mean either greater returns on investment at $30 \%$ genetic gain or better, or will make the use of lower genetic gain economic. Cost reductions could also be realized through the automation of labour intensive steps such as shoot separation. Already a method involving automated pattern recognition is being developed in Australia with a design productivity of 3,600 shoots/h (Hartney 1985). Other developments, such as the Rutgers University procedure (Hamilton, Pederson and Chin 1985) of using flat microporous rafts to support growth of plant tissues on liquid medium, thus facilitating medium change, will contribute to improvements in the technology and decreased costs. The potential for cost reductions through technological developments is in the order of $\$ 100$ to $\$ 200 / 1000$ plantlets.

Just as important as the development of tissue culture methods is the need for progress in tree breeding and improvements programs. There is the obvious need for increasing growth rates and decreasing rotation age to make forestry in general more competitive internationally. Tissue culture can be an economic means for delivering more quickly the improved characteristics to the forest if the gain is sufficient to counterbalance the additional investment. Furthermore, if improved traits can be stacked to give not just increased growth rate but also, for example, disease and insect resistance, increased specific gravity and fibre content, and possibly drought and cold tolerance, then it becomes all the more important to develop and implement tissue culture methods in forestry.

To fully exploit the opportunities of micropropagation and other tissue cuiture methods for forestry, the technologies and the infrastructure for delivering them must be systematically developed. The following is a list of priority areas for research, development and demonstration required to reach the commercialization of these technologies.

1. Development of micropropagation protocols from juvenile and mature tissue of commercially important conifers.

2. Increased effort in conifer breeding with the selection of improved full-sib families and the development of early testing methods for desirable traits.

3. Within family selection for superior individuals and clonal testing using mature or adolescent tissue culture methods.

4. Research on the production of haploid plants through tissue culture to assist conifer improvement and genetics work.

5. Development of methods for cold storage of clones during clonal trials.

6. Scale-up of micropropagation methods for demonstrating commercial feasibility and for producing clones for large scale field trials.

7. Development of improved protocols for micropropagation and somatic embryogenesis including research lowards a better understanding of the biochemical and developmental basis of plant regeneration from cell and tissue culture.

8. Automation of tissue culture facilities. 
9. Research on the use of tissue and callus culture for inducing somaclonal variation for the development and selection of traits such as disease resistance.

10. Development of advanced molecular genetics methods for manipulating specific genes and for the study of conifer genetics.

The above list is a broad outline of priority activities that need to be pursued. Within this framework many more subtopics could be elaborated.

One question that still remains unanswered is what is the comparative potential of using micropropagation versus macropropagation. The latter at present is less expensive than the current tissue culture procedure described in this paper. Our back-of-the-envelope estimate of the cost of producing rooted black spruce cuttings by the procedure developed by the Ontario Ministry of Natural Resources (Phillion 1982) is about $\$ 300 / 1000$ plants. Arnold and Gleed (1985) of Tasman Forestry Ltd. in New Zealand have presented detailed costing for rooted cuttings production and arrived at a cost of $\$ 223 \mathrm{NZ} / 1000$ plants. In comparison, Smith (1985) estimated a probable cost of about $\$ 450 \mathrm{NZ}$ / 1000 tissue cultured plantlets (1983 NZ\$).

From our evaluation it appears that the production of rooted cuttings according to the procedure detailed by Phillion (1982) for black spruce will be competitive with seedlings which cost $\$ 200 / 1000$ at about $15 \%$ genetic gain, if the gain is utilized for reducing rotation age (the actual cost of black spruce seedlings may be about $\$ 100$ to $\$ 150 / 1000)$. This is about half the gain required to make tissue culture competitive with seedlings. However, there is the potential with tissue culture methods for exploiting greater gains through cold storage of cultures during progeny trials. Also, potential exists for using mature tissues from elite individuals, while cutting programs from mature stock have not proven very successful. Lastly, it is possible that macropropagation may not work as effectively on all species as for black spruce. These species that are more resistant to rooting could possibly be more effectively cultured in vitro. The correct decisions on whether to use cuttings or tissue culture in operational forestry may depend on the species and, finally, on side-by-side demonstration of seedlings, rooted cuttings and tissue cultured plantlets.

\section{References}

Aitken-Christie, J. 1985. A subculturable meristematic callus system for shoot formation in radiata pine. Reported at the International Conifer Tissue Culture Work Group (ICTCWG) meeting, Rotorua, New Zealand, 12-16 August, 1985.

Arnold, R. and J.A. Gleed. 1985. Raising and managing radiata pine vegetative cuttings for production forests. Aust. For. (In press.)

Bayliss, M.W. 1980. Chromosomal variation in plant tissue cultures. Int. Rev. Cytol., Suppl. 11A:113.

D'Amato, F. 1975. The problem of genetic stability in plant tissue and cell cultures. In O.H. Frankel, and J.G. Hawkes (eds.), Crop Genetic Resources for Today and Tomorrow. Cambridge University Press. p. 333-348.
Dollezel, J. and F.J. Novák. 1984a. Cytogenetic effect of plant tissue culture medium with certain growth substances in Allium sativum meristem root tip cells. Biol. Plant. (Praha) 26: 293.

1984b. Effect of plant tissue culture media on the frequency of somatic mutations in Tradescantia stamen hairs. Z. Pflanzenphysiol. Bd. 114: 51.

Farnum, P., R. Timmis and J.L. Kulp. 1983. Biotechnology of forest yield. Science 219:694.

Frampton, Jr. L.J. 1985. Field performance of loblolly pine tissue culture plantlets. Reported at the ICTCWG meeting, Rotorua, New Zealand, 12-16 August, 1985.

Gleed, J. 1985. The commercial production of radiata pine by tissue culture methods: Some aspects and considerations. Reported at the ICTCWG meeting, Rotorua, New Zealand, 12-16 August, 1985.

Hakman, I., L.C. Fowke, S. von Arnold and T. Eriksson. 1985. The development of somatic embryos in tissue cultures initiated from immature embryos of Picea abies (Norway Spruce). Plant Science 38: 53.

Hamilton, R., H. Pederson and C.K. Chin. 1985. Plant tissue culture on membrane rafts. BioTechniques 3: 96 .

Hartney, V. Reported in a workshop at the ICTCWG meeting, Rotorua, New Zealand, 12-16 August, 1985.

Hasnain, S. and W. Cheliak. 1986. Tissue culture in forestry: Economic and genetic potential. For. Chron. 62: 219-225.

Mason, E. and F.W. Maine. 1984. Tissue culture and micropropagation for forest biomass production: Literature review. Division of Energy, National Research Council of Canada. NRCC Rept. 23776.

Nagl, W. 1984. DNA synthesis in tissue and cell cultures. In H.E. Street (ed.), Tissue Culture and Plant Science - 1974 Academic Press, New York. p. 19-42.

Phillion, B.J. 1982. Large-scale production of black spruce cuttings for progeny tests. Int. Plant Propag. Soc. 32: 619.

Rauter, R.M. 1983. Current status of macropropagation. In Proc. 19th Meet. Can. Tree Improv. Assoc., Part 2, Clonal forestry: Its impact on tree improvement and our future forests. Toronto, Ontario, 22-26 August, 1983. p. 58-74.

Ritchie, G.A. and A.J. Long. 1985. Field evaluation of micropropagated Douglas-fir. Reported at the ICTCWG meeting, Rotorua, New Zealand, 12-16 August, 1985

Smith. D.R. 1986. Forest and nut trees 1. Radiata pine Pinus radiata. In Y.P.S. Bajaj, ed. Biotechnology of Tree Improvement for Rapid Propagation and Biomass Energy Production. SpringerVerlag, Berlin. p 274-291

Smith, D.R., C.J.A. Shelbourne, M.J. Dibley and T. Carswell. 1985. Field performance of micropropagated Pinus radiata. Reported at the ICTCWG meeting, Rotorua, New Zealand, 1216 August, 1985

Thorpe, T.A. and S. Biondi. 1984. Fiber and wood: Conifers. In W.R Sharp, D.A. Evans, P.V. Amirato, and Y. Yamada, eds. Handbook of Plant Cell Culture: Crop Species Vol. 2. MacMillan Publishing Co., N.Y.

Timmis, R. 1984. Factors influencing the use of clonal materials in commercial forestry. International Union of Forest Research Organizations, Conf. on "Crop Physiology of Forest Trees". Helsinki. July, 1984

Zobel, B. and J. Talbert. 1984. Applied Forest Tree Improvement. John Wiley and Sons, Inc. p. 309-344. 